\title{
General Analysis of Timoshenko Beams on Elastic Foundation
}

\author{
S. Abohadima, M. Taha, and M. A. M. Abdeen \\ Department of Engineering Mathematics and Physics, Faculty of Engineering, Cairo University, Giza 12211, Egypt
}

Correspondence should be addressed to M. A. M. Abdeen; mtahtahab47@eng.cu.edu.eg

Received 1 September 2015; Accepted 8 October 2015

Academic Editor: Zhen-Lai Han

Copyright (C) 2015 S. Abohadima et al. This is an open access article distributed under the Creative Commons Attribution License, which permits unrestricted use, distribution, and reproduction in any medium, provided the original work is properly cited.

\begin{abstract}
General analytical solutions for stability, free and forced vibration of an axially loaded Timoshenko beam resting on a two-parameter foundation subjected to nonuniform lateral excitation are obtained using recursive differentiation method (RDM). Elastic restraints for rotation and translation are assumed at the beam ends to investigate the effect of support weakening on the beam behavior. However, the effects of rotational inertia and shear stress induced from the axial load are considered. The obtained solutions are verified first and then used to investigate the significance of different parameters on the beam behavior. In addition, solutions of forced vibration are analyzed to highlight the effects of excitation nonhomogeneity on the beam behavior.
\end{abstract}

\section{Introduction}

The static and dynamic analysis of Timoshenko beams with different configurations are of great importance for the design of many engineering applications. Analytical solutions are limited to study the behavior of Timoshenko beams with simple configuration due to the mathematical complexity of the problem. Ruta [1] used Chebyshev polynomials to study nonprismatic Timoshenko beams. The invalidation of BernoulliEuler theory for the cases of free-free and pinned-free shear beams has been discussed by Kausel [2]. Attarnejad et al. [3] applied the differential transform (DT) to investigate the free vibration of Timoshenko beams resting on two-parameter elastic foundations. Taha and Nassar [4] studied free and forced vibration of stressed Timoshenko beams resting on two-parameter foundations using the Adomian decomposition method (ADM). Free and forced vibrations of Timoshenko beams, described by a single difference equation, have been studied by Majkut [5].

On the other hand, numerical methods are used in the analysis of Timoshenko beams with complex configurations. Cheng and Pantelides [6] studied Euler and Timoshenko beams using continuous models and the stiffness matrix method. Geist and Mclaughlin [7] discussed the phenomenon of double frequencies in Timoshenko beams at certain values of beam slenderness ratios. Chen [8] used differential quadrature element method (DQEM) to study the vibration of nonprismatic shear deformable beams resting on elastic foundations. Monsalve et al. [9] presented dynamic analysis of Timoshenko beam-column with generalized end conditions on an elastic foundation using finite element method (FEM). Kocaturk and Simsek [10] investigated the vibration of Timoshenko beams under various boundary conditions using Lagrange equations and used Lagrange multipliers to account for different cases of boundary conditions. Nguyen [11] studied the vibration of prestressed Timoshenko beams either fully or partially supported on an elastic foundation using the finite element method (FEM). Auciello [12] used the Rayleigh-Ritz approach and boundary characteristic orthogonal polynomials are chosen as trial functions to investigate the vibration of Timoshenko beams on two-parameter foundations.

Analytical solutions for boundary value problems are always preferable compared to numerical solutions as they are more general and give a better understanding of the model behavior. On the other hand, unfortunately, analytical solutions are limited to simple and idealized models. Recursive differentiation method (RDM) is an efficient analytical method proposed by Taha [13] for tackling boundary value problems governed by linear or nonlinear differential equations. The method constructs analytical solutions based on Taylor expansion and can deal with complicated 
configurations of beam-foundation systems in finite domain. Taha and Doha [14] used RDM to study dynamics of beamfoundation systems assuming Euler-Bernoulli hypothesis.

In the present paper, RDM is implemented to obtain analytical solutions for the differential equations governing the static and dynamic behavior of axially loaded Timoshenko beams resting on two-parameter foundation with elastic end restraints and subjected to nonuniform lateral excitation. Both the influence of rotational inertia and the shear stress induced from the effect of axial load proposed by Timoshenko and Gere [15] will be considered. The stability behavior of cantilever Timoshenko beam resting on elastic foundation will be analyzed. In addition, the influences of the elastic end restraints weakening will be studied. Further, the significance of different parameters on the maximum lateral response amplitude of the beam due to different types of lateral excitation will be investigated.

\section{Formulation of the Governing Equations}

2.1. Dynamic Equations of Timoshenko Beams. The equations of translational and angular motion of an infinitesimal element of an axially loaded Timoshenko beam subjected to lateral excitation resting on two-parameter foundation shown in Figure 1 are

$$
\begin{array}{r}
\frac{\partial V}{\partial x}+q(x, t)-k_{1} y(x, t)+k_{2} \frac{\partial^{2} y}{\partial x^{2}}=\rho A \frac{\partial^{2} y}{\partial t^{2}} \\
V(x, t)+p \frac{\partial y}{\partial x}+\frac{\partial M}{\partial x}=\rho I \frac{\partial^{2} \theta}{\partial t^{2}}
\end{array}
$$

The force-displacement relations considering additional shear stress induced from the component of the axial load in the direction of the deformed section $(p \sin (\alpha) \cong p \alpha(x, t))$ proposed by Timoshenko and Gere [15] are

$$
\begin{aligned}
M(x, t) & =E I \frac{\partial \theta}{\partial x} . \\
V(x, t)+p \alpha(x, t) & =A_{s} G \gamma(x, t) .
\end{aligned}
$$

The relation between the deformation components of the beam element (shown in Figure 1(c)) is

$$
\frac{\partial y}{\partial x}=\theta+\gamma
$$

where $E$ is the modulus of elasticity of the beam material, $I$ is the moment of inertia of the beam cross section, $\rho$ is the density, $A$ is the area of the cross section, $A_{s}=\kappa A$ is the effective shear area, $\kappa$ is a correction factor to take into account the nonuniform distribution of shear stress $(\kappa=2 / 3$ for rectangular cross section), $p$ is the axial applied load, $k_{1}$ and $k_{2}$ are the linear and shear foundation stiffness factors per unit length of the beam, $q(x, t)$ is the lateral excitation acting on the beam, $\theta(x, t)$ is the rotation of the beam cross section, $\gamma$ is the deformation angle due to the shear force, $\alpha(x, t)$ is the angle between the axial load $p$ and the normal to the deformed cross section, $V(x, t)$ is the shear force, $M(x, t)$ is the bending moment, $y(x, t)$ is the lateral response of the beam, $x$ is the coordinate along the beam, and $t$ is the time.

Substituting (3), (4), and (5) into (1) and (2), the equations of motion may be expressed as

$$
\begin{aligned}
& A_{s} G\left(\frac{\partial^{2} y}{\partial x^{2}}-\frac{\partial \theta}{\partial x}\right)-p \frac{\partial \alpha}{\partial x}-k_{1} y+k_{2} \frac{\partial^{2} y}{\partial x^{2}}-\rho A \frac{\partial^{2} y}{\partial t^{2}} \\
& =-q(x, t), \\
& A_{s} G\left(\frac{\partial y}{\partial x}-\theta\right)-p \alpha+p \frac{\partial y}{\partial x}+E I \frac{\partial^{2} \theta}{\partial x^{2}}-\rho I \frac{\partial^{2} \theta}{\partial t^{2}}=0 .
\end{aligned}
$$

Introducing the dimensionless variables $\xi=x / L$ and $w=$ $y / L$, then (6) may be expressed as

$$
\begin{aligned}
& A_{s} G \frac{\partial \theta}{\partial \xi}+p \frac{\partial \alpha}{\partial \xi}-\left(A_{s} G+k_{2}\right) \frac{\partial^{2} w}{\partial \xi^{2}}+L^{2} k_{1} w \\
& +\rho A L^{2} \frac{\partial^{2} w(\xi)}{\partial t^{2}}=L q(\xi), \\
& A_{s} G \theta(\xi, t)+p \alpha(\xi, t)-\left(A_{s} G+p\right) \frac{\partial w}{\partial \xi}-\frac{E I}{L^{2}} \frac{\partial^{2} \theta}{d \xi^{2}} \\
& \quad+\rho A r^{2} \frac{\partial^{2} \theta}{\partial t^{2}}=0 .
\end{aligned}
$$

Assuming harmonic excitation, hence the responses are expected to be harmonic; then,

$$
\begin{aligned}
& q(\xi, t)=q(\xi) e^{i \Omega t} \\
& w(\xi, t)=\varphi(\xi) e^{i \Omega t}, \\
& \theta(\xi, t)=\psi(\xi) e^{i \Omega t}, \\
& \alpha(\xi, t)=\alpha(\xi) e^{i \Omega t},
\end{aligned}
$$

where $\Omega$ is the excitation frequency. Most of the practical cases for nonuniform continuous loading function can be closely simulated by assuming quadratic loading function in the form

$$
q(x)=q_{0}+q_{1} x+q_{2} x^{2} .
$$

Substituting (8) into (7),

$$
\begin{aligned}
& A_{s} G \frac{d \psi}{d \xi}+p \frac{d \alpha}{d \xi}-\left(A_{s} G+k_{2}\right) \frac{d^{2} \varphi}{d \xi^{2}} \\
& \quad+L^{2}\left(k_{1}-\rho A \Omega^{2}\right) \varphi(\xi)=L q(\xi), \\
& A_{s} G \psi(\xi)+p \alpha(\xi)-\left(A_{s} G+p\right) \frac{d \varphi}{d \xi}-\frac{E I}{L^{2}} \frac{d^{2} \psi}{d \xi^{2}} \\
& \quad-\rho A r^{2} \Omega^{2} \psi(\xi)=0 .
\end{aligned}
$$

2.2. Additional Shear Induced from the Axial Load. There are three approaches in dealing with the shear stress induced from the axial load: the first approach neglects the additional 


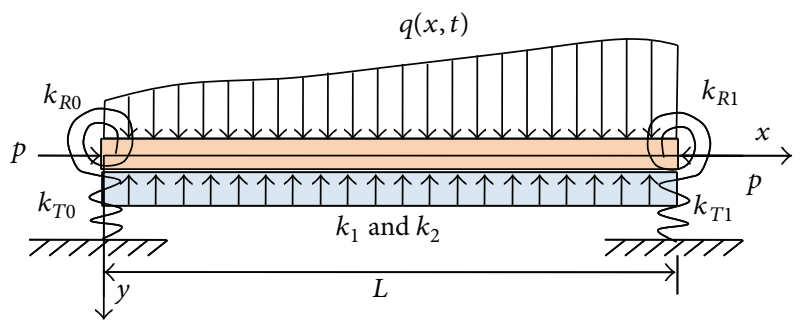

(a)

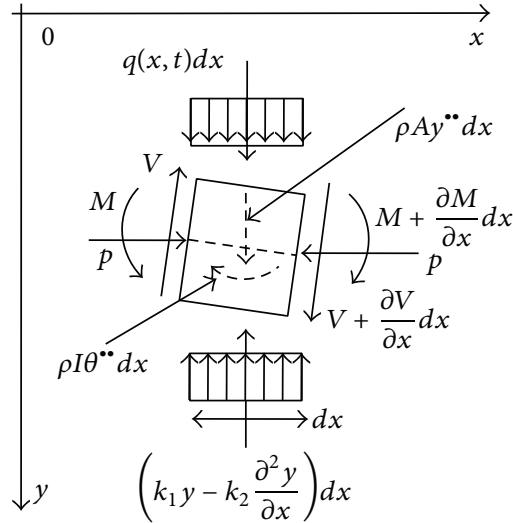

(b)

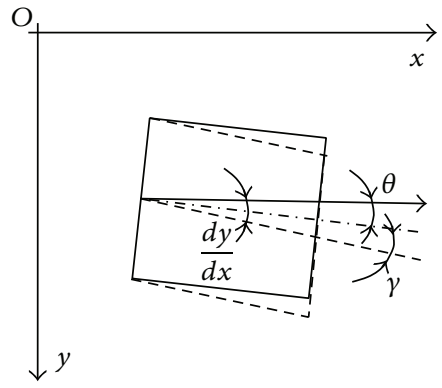

(c)

FIgURE 1: (a) Timoshenko beam on elastic foundation. (b) Element forces. (c) Total deformation.

shear stress, the second approach assumes the inclination angle between the axial load and the outward normal to the deformed cross section $\alpha(x, t)=\theta(x, t)$, and the third approach assumes $\alpha(x, t)=\partial y / \partial t$.

According to the first approach $(\alpha(\xi)=0),(10)$ may be rewritten as

$$
\begin{aligned}
& A_{s} G \frac{d \psi}{d \xi}-\left(A_{s} G+k_{2}\right) \frac{d^{2} \varphi}{d \xi^{2}}+L^{2}\left(k_{1}-\rho A \Omega^{2}\right) \varphi(\xi) \\
& \quad=L q(\xi)
\end{aligned}
$$

$$
\begin{aligned}
& A_{s} G \psi(\xi)-\left(A_{s} G+p\right) \frac{d \varphi}{d \xi}-\frac{E I}{L^{2}} \frac{d^{2} \psi}{d \xi^{2}}-\rho A r^{2} \Omega^{2} \psi(\xi) \\
& \quad=0 .
\end{aligned}
$$

Defining the dimensionless parameters,

$$
\begin{aligned}
S^{2} & =\frac{A_{s} G L^{2}}{E I}=\frac{\kappa \eta^{2}}{2(1+\nu)}, \\
\lambda_{F}^{4} & =\frac{\rho A \Omega^{2} L^{4}}{E I}, \\
\eta & =\frac{L}{r}, \\
r & =\sqrt{\frac{I}{A}},
\end{aligned}
$$

$$
\begin{aligned}
P & =\frac{p L^{2}}{E I}, \\
K_{1} & =\frac{k_{1} L^{4}}{E I}, \\
K_{2} & =\frac{k_{2} L^{2}}{E I} .
\end{aligned}
$$

Using the dimensionless parameters defined in (12), (11) may be expressed as

$$
\frac{d \psi}{d \xi}=\frac{\sigma_{2}}{S^{2}} \frac{d^{2} \varphi}{d \xi^{2}}-\frac{\sigma_{1}}{S^{2}} \varphi(\xi)+\frac{Q(\xi)}{S^{2}},
$$

$$
\frac{d^{2} \psi}{d \xi^{2}}+\sigma_{0} \frac{d \varphi}{d \xi}-\sigma_{3} \psi(\xi)=0,
$$

where

$$
\begin{gathered}
\sigma_{0}=S^{2}+P, \\
\sigma_{1}=K_{1}-\lambda_{F}^{4}, \\
\sigma_{2}=S^{2}+K_{2}, \\
\sigma_{3}=S^{2}-\frac{\lambda_{F}^{4}}{\eta^{2}}, \\
Q(\xi)=\frac{L^{3}}{E I} q(\xi),
\end{gathered}
$$


where $S$ is the slenderness parameter, $\lambda_{F}$ is the frequency parameter, $\eta$ is the slenderness ratio, $r$ is the radius of gyration, $P$ is the axial load parameter, $K_{1}$ is the foundation linear stiffness parameter, and $K_{2}$ is the foundation shear stiffness parameter.

Inserting (14) into (13), the equation describing the lateral response amplitude of the Timoshenko beam based on the first approach is

$$
\begin{aligned}
& \frac{d^{4} \varphi}{d \xi^{4}}-\left(\frac{\sigma_{1}+\sigma_{2} \sigma_{3}-\sigma_{0} S^{2}}{\sigma_{2}}\right) \frac{d^{2} \varphi}{d \xi^{2}}+\frac{\sigma_{1} \sigma_{3}}{\sigma_{2}} \varphi(\xi) \\
& =\frac{\sigma_{3} Q-Q^{\prime \prime}}{\sigma_{2}} .
\end{aligned}
$$

Similarly, for the second approach $(\alpha(\xi)=\psi(\xi))$, (11) may be expressed as

$$
\frac{d \psi}{d \xi}=\frac{\sigma_{2}}{\sigma_{0}} \frac{d^{2} \varphi}{d \xi^{2}}-\frac{\sigma_{1}}{\sigma_{0}} \varphi(\xi)+\frac{Q(\xi)}{\sigma_{0}},
$$

$$
\frac{d^{2} \psi}{d \xi^{2}}+\sigma_{0} \frac{d \varphi}{d \xi}-\sigma_{4} \psi(\xi)=0
$$

Also, the equation of the lateral response amplitude of the Timoshenko beam according to the second approach is

$$
\begin{gathered}
\frac{d^{4} \varphi}{d \xi^{4}}-\left(\frac{\sigma_{1}+\sigma_{2} \sigma_{4}-\sigma_{0}^{2}}{\sigma_{2}}\right) \frac{d^{2} \varphi}{d \xi^{2}}+\frac{\sigma_{1} \sigma_{4}}{\sigma_{2}} \varphi(\xi) \\
=\frac{\sigma_{4} Q-Q^{\prime \prime}}{\sigma_{2}},
\end{gathered}
$$

where $\sigma_{4}=P+\sigma_{3}$.

According to the third approach $(\alpha(\xi)=d \varphi / d \xi)$, the dynamic equations of lateral response amplitude can be obtained as

$$
\begin{aligned}
& \frac{d \psi}{d \xi}=\frac{\sigma_{5}}{S^{2}} \frac{d^{2} \varphi}{d \xi^{2}}-\frac{\sigma_{1}}{S^{2}} \varphi(\xi)+\frac{Q(\xi)}{S^{2}}, \\
& \frac{d^{2} \psi}{d \xi^{2}}+S^{2} \frac{d \varphi}{d \xi}-\sigma_{3} \psi(\xi)=0, \\
& \frac{d^{4} \varphi}{d \xi^{4}}-\left(\frac{\sigma_{1}+\sigma_{3} \sigma_{5}-S^{4}}{\sigma_{5}}\right) \frac{d^{2} \varphi}{d \xi^{2}}+\frac{\sigma_{1} \sigma_{3}}{\sigma_{5}} \varphi(\xi) \\
& =\frac{\sigma_{3} Q(\xi)-Q^{\prime \prime}}{\sigma_{5}},
\end{aligned}
$$

where

$$
\sigma_{5}=\sigma_{2}-P .
$$

The dynamic equations of different approaches may be expressed as

$$
\begin{gathered}
\frac{d \psi}{d \xi}=B_{1} \frac{d^{2} \varphi}{d \xi^{2}}+B_{2} \varphi(\xi)+B_{3} Q(\xi), \\
\psi(\xi)=B_{4} \frac{d^{3} \varphi}{d \xi^{3}}+B_{5} \frac{d \varphi}{d \xi}+B_{6} Q^{\prime}(\xi),
\end{gathered}
$$

where parameters $B_{i}$ for the first approach are defined as

$$
\begin{aligned}
& B_{1}=\frac{\sigma_{2}}{S^{2}}, \\
& B_{2}=-\frac{\sigma_{1}}{S^{2}}, \\
& B_{3}=\frac{1}{S^{2}}, \\
& B_{4}=\frac{\sigma_{2}}{S^{2} \sigma_{3}}, \\
& B_{5}=\frac{S^{2} \sigma_{0}-\sigma_{1}}{S^{2} \sigma_{3}}, \\
& B_{6}=\frac{1}{S^{2} \sigma_{3}} .
\end{aligned}
$$

And, for the second approach, they are defined as

$$
\begin{aligned}
& B_{1}=\frac{\sigma_{2}}{\sigma_{0}}, \\
& B_{2}=-\frac{\sigma_{1}}{\sigma_{0}}, \\
& B_{3}=\frac{1}{\sigma_{0}}, \\
& B_{4}=\frac{\sigma_{2}}{\sigma_{0} \sigma_{4}}, \\
& B_{5}=\frac{\sigma_{0}^{2}-\sigma_{1}}{\sigma_{0} \sigma_{4}}, \\
& B_{6}=\frac{1}{\sigma_{0} \sigma_{4}} .
\end{aligned}
$$

For the third approach, they are defined as

$$
\begin{aligned}
& B_{1}=\frac{\sigma_{5}}{S^{2}}, \\
& B_{2}=-\frac{\sigma_{1}}{S^{2}}, \\
& B_{3}=\frac{1}{S^{2}}, \\
& B_{4}=\frac{\sigma_{5}}{S^{2} \sigma_{3}}, \\
& B_{5}=\frac{S^{4}-\sigma_{1}}{S^{2} \sigma_{3}}, \\
& B_{6}=\frac{1}{S^{2} \sigma_{3}} .
\end{aligned}
$$

2.3. Boundary Conditions due to Elastic Restraints. For the case of the elastic restraints at both ends, the physical boundary conditions at beam ends are

$$
\begin{aligned}
\text { at } x & =0, \\
V(0, t) & =-k_{T 0} y(0, t), \\
M(0, t) & =k_{R 0} \theta(0, t) ;
\end{aligned}
$$




$$
\begin{aligned}
\text { at } x & =L, \\
V(L, t) & =k_{T 1} y(L, t), \\
M(L, t) & =-k_{R 1} \theta(L, t) .
\end{aligned}
$$

Using the dimensionless variables $\xi$ and $\varphi$ and (2), (3), and (23), the boundary conditions in dimensionless form assuming the first approach $(\alpha(\xi)=0)$ may be obtained as

$$
\begin{aligned}
& \frac{d^{3} \varphi}{d \xi^{3}}+\left(\frac{B_{5}-1}{B_{4}}\right) \frac{d \varphi}{d \xi}-\frac{K_{T 0}}{S^{2} B_{4}} \varphi(0)=\frac{-B_{6}}{B_{4}} Q^{\prime}(0) \\
& \frac{d^{3} \varphi}{d \xi^{3}}-\frac{B_{1}}{B_{4} K_{R 0}} \frac{d^{2} \varphi}{d \xi^{2}}+\frac{B_{5}}{B_{4}} \frac{d \varphi}{d \xi}-\frac{B_{2}}{B_{4} K_{R 0}} \varphi(0) \\
& =\frac{B_{3} Q(0)-B_{6} K_{R 0} Q^{\prime}(0)}{B_{4} K_{R 0}} \\
& \frac{d^{3} \varphi}{d \xi^{3}}+\left(\frac{B_{5}-1}{B_{4}}\right) \frac{d \varphi}{d \xi}+\frac{K_{T 1}}{S^{2} B_{4}} \varphi(1)=\frac{-B_{6}}{B_{4}} Q^{\prime}(1) \\
& \frac{d^{3} \varphi}{d \xi^{3}}+\frac{B_{1}}{B_{4} K_{R 1}} \frac{d^{2} \varphi}{d \xi^{2}}+\frac{B_{5}}{B_{4}} \frac{d \varphi}{d \xi}+\frac{B_{2}}{B_{4} K_{R 1}} \varphi(1) \\
& =-\frac{B_{3} Q(1)+B_{6} K_{R 0} Q^{\prime}(1)}{B_{4} K_{R 1}} .
\end{aligned}
$$

For the second approach $(\alpha(\xi)=\psi(\xi))$, the boundary conditions can be expressed as

$$
\begin{aligned}
& \frac{d^{3} \varphi}{d \xi^{3}}+\left(\frac{\sigma_{0} B_{5}-S^{2}}{\sigma_{0} B_{4}}\right) \frac{d \varphi}{d \xi}-\frac{K_{T 0}}{\sigma_{0} B_{4}} \varphi(0)=\frac{-B_{6}}{B_{4}} Q^{\prime}(0) \\
& \frac{d^{3} \varphi}{d \xi^{3}}-\frac{B_{1}}{B_{4} K_{R 0}} \frac{d^{2} \varphi}{d \xi^{2}}+\frac{B_{5}}{B_{4}} \frac{d \varphi}{d \xi}-\frac{B_{2}}{B_{4} K_{R 0}} \varphi(0) \\
& =\frac{B_{3} Q(0)-B_{6} K_{R 0} Q^{\prime}(0)}{B_{4} K_{R 0}} \\
& \frac{d^{3} \varphi}{d \xi^{3}}+\left(\frac{\sigma_{0} B_{5}-S^{2}}{\sigma_{0} B_{4}}\right) \frac{d \varphi}{d \xi}+\frac{K_{T 1}}{\sigma_{0} B_{4}} \varphi(1)=\frac{-B_{6}}{B_{4}} Q^{\prime}(1) \\
& \frac{d^{3} \varphi}{d \xi^{3}}+\frac{B_{1}}{B_{4} K_{R 1}} \frac{d^{2} \varphi}{d \xi^{2}}+\frac{B_{5}}{B_{4}} \frac{d \varphi}{d \xi}+\frac{B_{2}}{B_{4} K_{R 1}} \varphi(1) \\
& =-\frac{B_{3} Q(1)+B_{6} K_{R 1} Q^{\prime}(1)}{B_{4} K_{R 1}} .
\end{aligned}
$$

On the other hand, for the third approach $\left(\alpha(\xi)=\varphi^{\prime}(\xi)\right)$, the boundary conditions can be expressed as

$$
\frac{d^{3} \varphi}{d \xi^{3}}+\left(\frac{S^{2} B_{5}-\sigma_{6}}{S^{2} B_{4}}\right) \frac{d \varphi}{d \xi}+\frac{K_{T 0}}{S^{2} B_{4}} \varphi(0)=\frac{-B_{6}}{B_{4}} Q^{\prime}(0)
$$

$$
\begin{aligned}
& \frac{d^{3} \varphi}{d \xi^{3}}-\frac{B_{1}}{B_{4} K_{R 0}} \frac{d^{2} \varphi}{d \xi^{2}}+\frac{B_{5}}{B_{4}} \frac{d \varphi}{d \xi}-\frac{B_{2}}{B_{4} K_{R 0}} \varphi(0) \\
& =\frac{B_{3} Q(0)-B_{6} K_{R 0} Q^{\prime}(0)}{B_{4} K_{R 0}} \\
& \frac{d^{3} \varphi}{d \xi^{3}}+\left(\frac{S^{2} B_{5}-\sigma_{6}}{S^{2} B_{4}}\right) \frac{d \varphi}{d \xi}-\frac{K_{T 1}}{S^{2} B_{4}} \varphi(1)=\frac{-B_{6}}{B_{4}} Q^{\prime}(1) \\
& \frac{d^{3} \varphi}{d \xi^{3}}+\frac{B_{1}}{B_{4} K_{R 1}} \frac{d^{2} \varphi}{d \xi^{2}}+\frac{B_{5}}{B_{4}} \frac{d \varphi}{d \xi}+\frac{B_{2}}{B_{4} K_{R 1}} \varphi(1) \\
& =-\frac{B_{3} Q(1)+B_{6} K_{R 1} Q^{\prime}(1)}{B_{4} K_{R 1}},
\end{aligned}
$$

where

$$
\begin{aligned}
\sigma_{6} & =S^{2}-P, \\
K_{T 0} & =\frac{L^{3} k_{T 0}}{E I}, \\
K_{R 0} & =\frac{L k_{R 0}}{E I}, \\
K_{T 1} & =\frac{L^{3} k_{T L}}{E I}, \\
K_{R 1} & =\frac{L k_{R L}}{E I} .
\end{aligned}
$$

\section{Solution of the Governing Equations}

3.1. Applications of the RDM to the Governing Equations. To use RDM, the response amplitude equations, (16), (18), or (21), are to be rewritten in the recursive form

$$
\begin{aligned}
\varphi^{(4)}(\xi)= & A_{1,1} \varphi^{(0)}+A_{1,2} \varphi^{(1)}+A_{1,3} \varphi^{(2)}+A_{1,4} \varphi^{(3)} \\
& +F_{1}(\xi)
\end{aligned}
$$

where $\varphi^{(m)}$ is the $m$-derivative of $\varphi$. Coefficients $A_{i, j}$ for the first approach are

$$
\begin{aligned}
A_{1,1} & =-\frac{\sigma_{1} \sigma_{3}}{\sigma_{2}}, \\
A_{1,2} & =0 \\
A_{1,3} & =\frac{\sigma_{1}+\sigma_{2} \sigma_{3}-\sigma_{0} S^{2}}{\sigma_{2}}, \\
A_{1,4} & =0, \\
F_{1}(\xi) & =\frac{\sigma_{3} Q-Q^{\prime \prime}}{\sigma_{2}} .
\end{aligned}
$$

For the second approach, coefficients $A_{i, j}$ are

$$
\begin{aligned}
& A_{1,1}=-\frac{\sigma_{1} \sigma_{4}}{\sigma_{2}}, \\
& A_{1,2}=0,
\end{aligned}
$$


TABLE 1: Values of frequency parameters of the first three vibration modes.

\begin{tabular}{|c|c|c|c|c|c|c|c|c|c|}
\hline \multirow[b]{2}{*}{$P$} & \multicolumn{2}{|c|}{ Parameters } & \multirow{2}{*}{$\begin{array}{l}\text { Case } \\
\text { Mode }\end{array}$} & \multicolumn{3}{|c|}{ P-P beams } & \multicolumn{3}{|c|}{ C-P beams } \\
\hline & $K_{1}$ & $K_{2}$ & & $\lambda_{1}$ & $\lambda_{2}$ & $\lambda_{3}$ & $\lambda_{1}$ & $\lambda_{2}$ & $\lambda_{3}$ \\
\hline \multirow{2}{*}{0} & \multirow{2}{*}{0} & \multirow{2}{*}{0} & Ritz & 2.867 & 4.922 & 6.445 & 3.26 & 5.061 & 6.483 \\
\hline & & & RDM & 2.866 & 4.922 & 6.445 & 3.26 & 5.061 & 6.483 \\
\hline \multirow{2}{*}{0.6} & \multirow{2}{*}{0} & \multirow{2}{*}{0} & Ritz & 1.861 & 4.391 & 5.927 & 2.706 & 4.575 & 5.979 \\
\hline & & & RDM & 1.863 & 4.384 & 5.923 & 2.706 & 4.575 & 5.979 \\
\hline \multirow{2}{*}{0.6} & \multirow{2}{*}{$0.6 \pi^{4}$} & \multirow{2}{*}{0} & Ritz & 2.866 & 4.544 & 6.011 & 3.237 & 4.712 & 6.042 \\
\hline & & & RDM & 2.866 & 4.538 & 5.988 & 3.237 & 4.712 & 6.042 \\
\hline \multirow{2}{*}{0.6} & \multirow{2}{*}{$0.6 \pi^{4}$} & \multirow{2}{*}{$\pi^{2}$} & Ritz & 3.555 & 5.299 & 6.796 & 3.797 & 5.408 & 6.803 \\
\hline & & & $\mathrm{RDM}$ & 3.555 & 5.294 & 6.777 & 3.797 & 5.408 & 6.803 \\
\hline
\end{tabular}

$$
\begin{aligned}
A_{1,3} & =\frac{\sigma_{1}+\sigma_{2} \sigma_{4}-\sigma_{0}^{2}}{\sigma_{2}}, \\
A_{1,4} & =0, \\
F_{1}(\xi) & =\frac{\sigma_{4} Q-Q^{\prime \prime}}{\sigma_{2}} .
\end{aligned}
$$

In addition, coefficients $A_{i, j}$ for the third approach are

$$
\begin{aligned}
A_{1,1} & =-\frac{\sigma_{1} \sigma_{3}}{\sigma_{5}}, \\
A_{1,2} & =0, \\
A_{1,3} & =\frac{\sigma_{1}+\sigma_{3} \sigma_{5}-S^{4}}{\sigma_{5}}, \\
A_{1,4} & =0, \\
F_{1}(\xi) & =\frac{\sigma_{3} Q-Q^{\prime \prime}}{\sigma_{5}} .
\end{aligned}
$$

The solution of (32) may be expressed as

$$
\varphi(\xi)=\sum_{m=1}^{4} T_{m} R_{m}(\xi)+R_{F}(\xi),
$$

where the recursive functions $R_{m}(\xi), m=1: 4$, and the force function $R_{F}(\xi)$ are given by

$$
\begin{aligned}
R_{m}(\xi) & =\frac{\xi^{m-1}}{(m-1) !}+\sum_{i=1}^{N} A_{i, m} \frac{\xi^{i+3}}{(i+3) !}, \quad m=1: 4 \\
R_{F}(\xi) & =\sum_{i=1}^{N} F_{i}(0) \frac{\xi^{i+3}}{(n+3) !} .
\end{aligned}
$$

The recurrence formulae for coefficients $A_{k+1, i}, k=1: N$, and $F_{i}$ are given by

$$
\begin{aligned}
A_{k+1,1} & =A_{k, 4} A_{1,1}, \\
A_{k+1, r} & =A_{k, r-1}+A_{k, 4} A_{1, r}, \quad r=2: n \\
F_{k+1}(\xi) & =F_{k}^{\prime}(\xi)+A_{k, 4} F_{1}(\xi) .
\end{aligned}
$$

The application of the boundary conditions (see (28a)-(28d), (29a)-(29d), or (30a)-(30d)) at $\xi=0,1$ yields a system of 4-algebraic equations in 4 unknowns, $T_{1}, T_{2}, T_{3}$, and $T_{4}$; however, calculating these unknowns, the response amplitude distribution, $\varphi(\xi)$, can be obtained.

The distribution of bending moment $M(\xi)$ and shearing force $V(\xi)$ may be obtained using (2) and (3), respectively.

\subsection{Calculations of Critical Loads and Natural Frequencies.} The critical loads and natural frequencies may be calculated by assuming zero excitation amplitude $(F(\xi)=0)$ and replacing the excitation frequency $\Omega$ by the natural frequency $\omega$ of the system. The substitution of $\varphi(\xi)$ and its derivatives into the boundary conditions yields a system of homogeneous algebraic equations whose nontrivial solution yields a twoparameter eigenvalue problem in $p$ and $\omega$. The solution of the two-parameter eigenvalue problem yields both critical loads $p_{\mathrm{cr} n}$ and buckling modes for static case $(\omega=0)$ and the natural frequencies of system $\omega_{n}$ and the mode shapes for free vibration $\left(p<p_{\mathrm{cr}}\right)$.

Also, critical loads and natural frequencies may be obtained from forced vibration by detecting the axial load or the excitation frequency at which the response amplitude becomes unbounded.

3.3. Verification of the Obtained Solutions. The natural frequency parameter of the lower three modes for Timoshenko beams $\lambda_{n}, i=1: 3$, is obtained using the present solution assuming the third approach and compared with those obtained from the Rayleigh-Ritz approach [12]. The comparison is indicated in Table 1 for different boundary conditions. It is found that the results of the two approaches are compatible.

\section{Numerical Results and Discussion}

The obtained solutions are used to investigate the influence of beam and foundation parameters on the stability parameters and dynamic behavior of Timoshenko beams. The foundation parameters $\left(K_{1}\right.$ and $\left.K_{2}\right)$ and beam properties are taken similar to those given in Taha and Doha [14].

However, for the investigation of the amplitude of the lateral response, the following normalized parameters are introduced:

$$
\gamma=\frac{P}{P_{\mathrm{cr}}}
$$




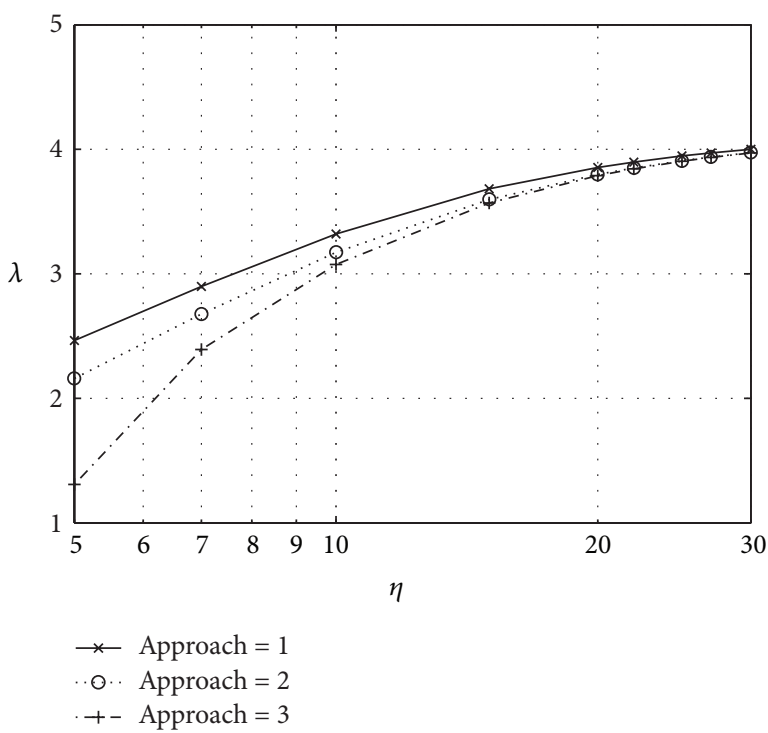

(a) No foundation $\left(E_{s}=0\right)$

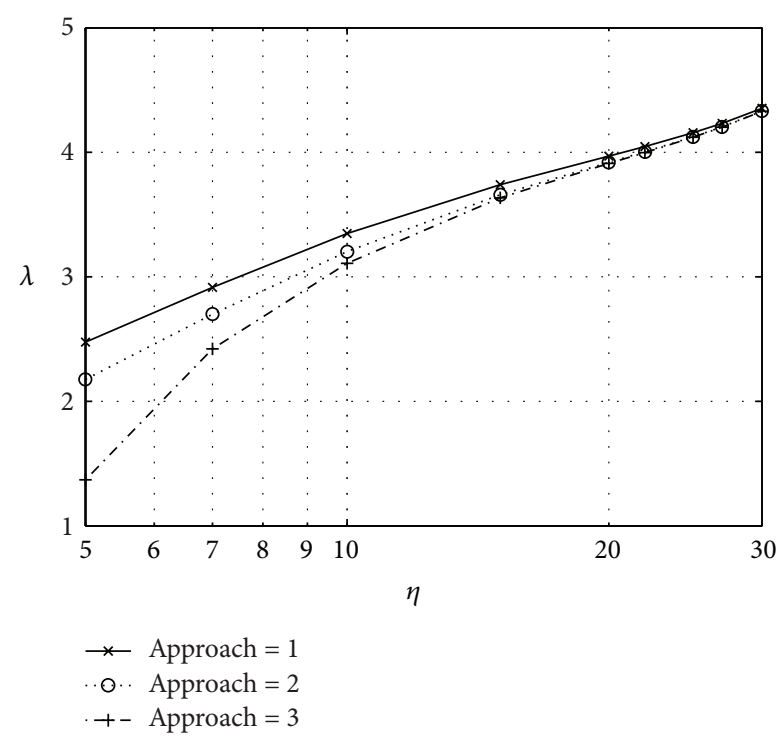

(b) Stiff foundation $\left(E_{s}=10^{8}\right)$

Figure 2: Variation of $\lambda$ with $\eta$ for C-F beams $\left(P=0.2 \pi^{2}\right)$.

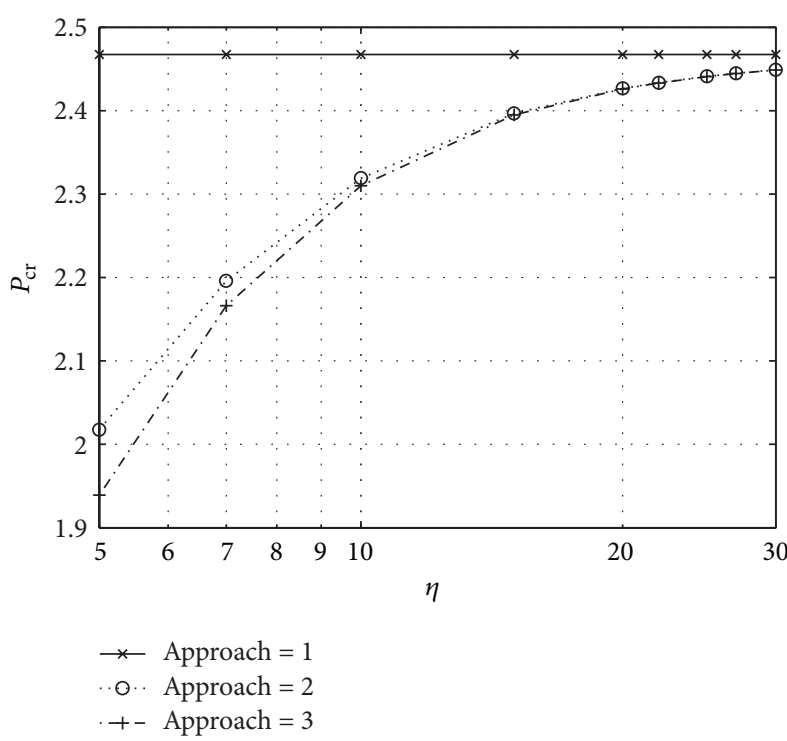

(a) No foundation

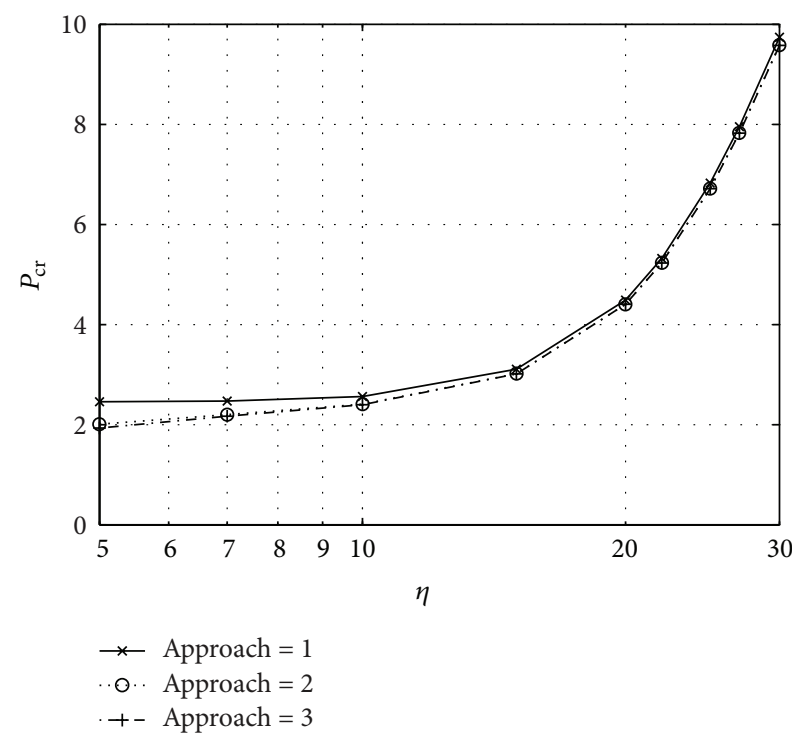

(b) Stiff foundation

Figure 3: Variation of $P_{\mathrm{cr}}$ with $\eta$ for C-F beams.

$$
W^{*}=\frac{W_{\max }}{W_{u-\max }},
$$

where $\gamma$ is the loading parameter, $W^{*}$ is the maximum amplitude parameter, $W_{\max }$ is the maximum amplitude of the investigated case, and $W_{u \text {-max }}$ is the maximum amplitude for the P-P corresponding case.

4.1. Stability Parameters for Cantilever Beams. Although many engineering applications belong to the Timoshenko cantilever beam model, a few articles are published concerning the stability and dynamic behavior of such model due to its mathematical complications. In the present work, the investigation of cantilever beam behavior is highlighted. The comparison between the different approaches dealing with the shear induced from the axial load on the frequency parameter $\lambda$ for clamped-free beams (C-F) is shown in Figure 2: case (a) for beams without foundation $\left(E_{s}=0\right)$ and case (b) for beams resting on stiff foundation $\left(E_{s}=10^{8}\right)$.

On the other hand, the influences of different approaches on quantifying the critical load of C-F beams are indicated in Figure 3: case (a) for beams without foundation and case (b) for beams on stiff foundations. It is obvious that considering the shear component induced from the axial load decreases 


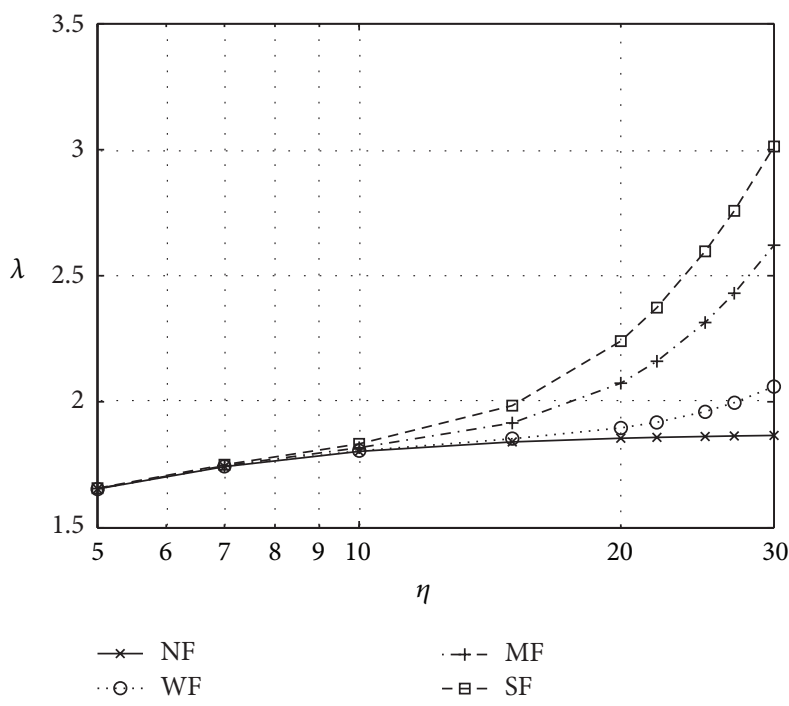

(a) $P=0$

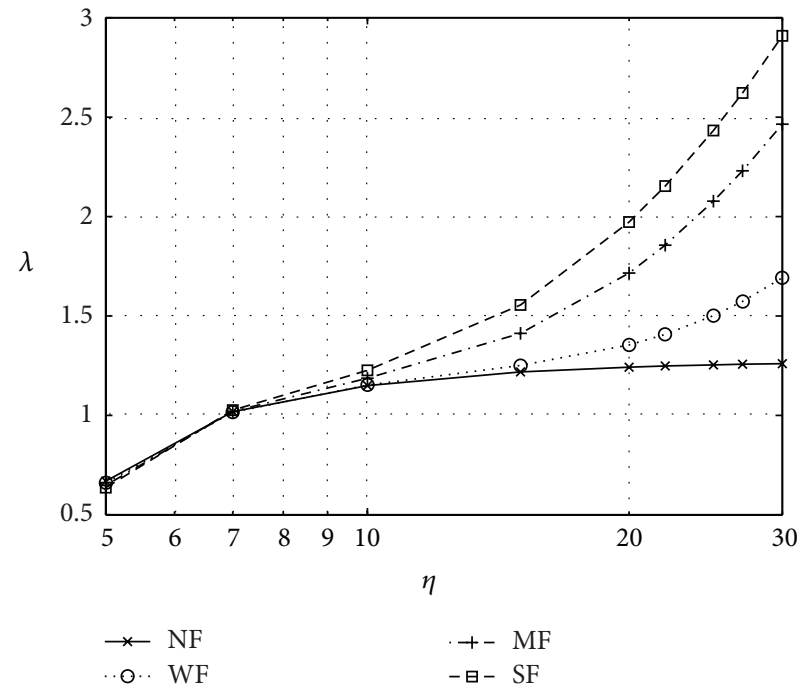

(b) $P=0.2 \pi^{2}$

FIgURE 4: Variation of $\lambda$ with $\eta$ for C-F beams.

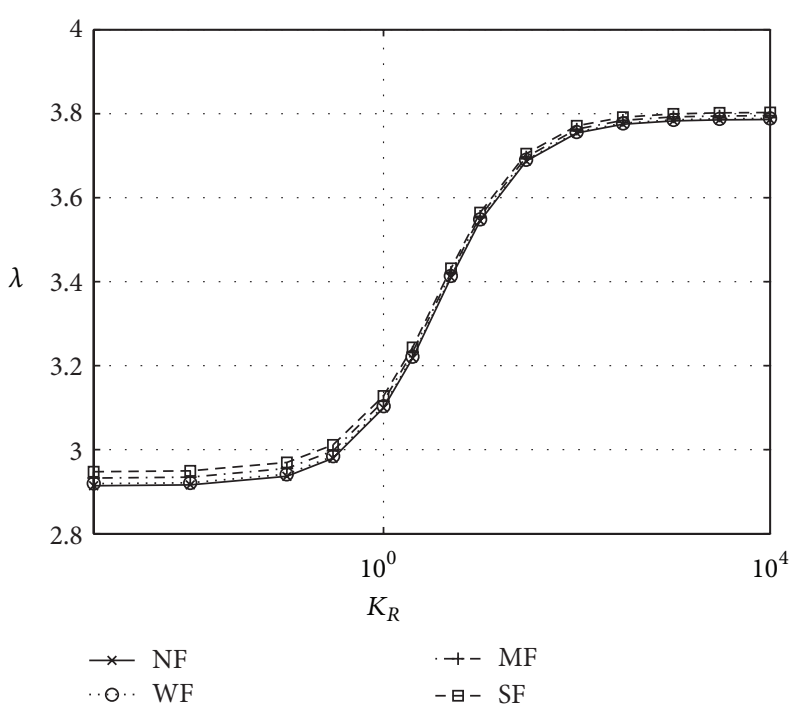

(a) Slenderness ratio $\eta=10$

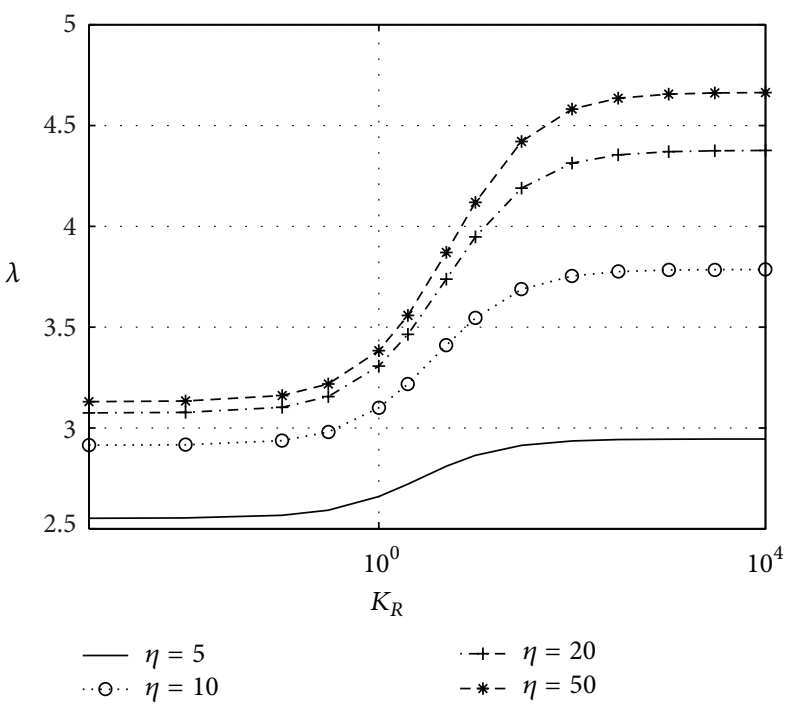

(b) No foundations $\left(E_{s}=0\right)$

FIGURE 5: Influence of $K_{R}$ on $\lambda$ for different types of foundation and for different $\eta(P=0)$.

the beam stiffness and the effect is noticeable for beams with slenderness ratio $\lambda<20$.

In the following analysis, the parametric study is based on the second approach as it is the rational one because the angle between the axial load and the outward normal to the deformed cross section $\alpha(x, t)$ is actually equal to the angle of cross section rotation $\psi(x, t)$ in the deformed configuration.

The influence of foundation type on the frequency parameter for C-F beams is shown in Figure 4. It is found that, as the slenderness ratio increases, the natural frequency of beams resting on foundation increases due to the increase of foundation share in the overall stiffness of the system. The increase in the natural frequency parameter is more noticeable for stiff foundations (SF). The critical load of Timoshenko C-F beam without foundation $P_{\mathrm{cr}}=0.21 \pi^{2}$.
4.2. Weakening of the End Restraints. The effect of rotational stiffness variations on the natural frequency parameter is shown in Figure 5(a) for different types of foundations $(\eta=$ $10)$ and in Figure 5(b) for different values of slenderness ratio $\left(E_{s}=0\right)$.

Further, the effect of rotational stiffness variations on the critical load parameter is shown in Figure 6(a) for different types of foundation $(\eta=10)$ and in Figure 6(b) for different values of slenderness ratio $\left(E_{s}=0\right)$.

The influence of rotational stiffness variations on the natural frequency parameter is shown in Figure 7 for different loading ratios and for the cases of no foundation $\left(E_{s}=0\right)$ and stiff foundations $\left(E_{s}=10^{8}\right)$.

It is obvious that the significance of real foundation types for Timoshenko beam behavior $(\eta<20)$ is negligible due to 


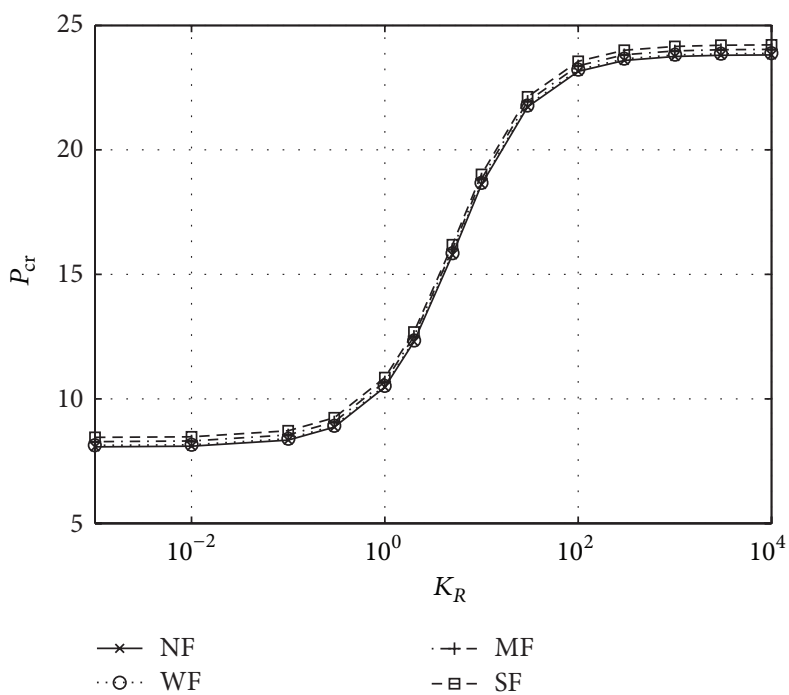

(a) $\eta=10$

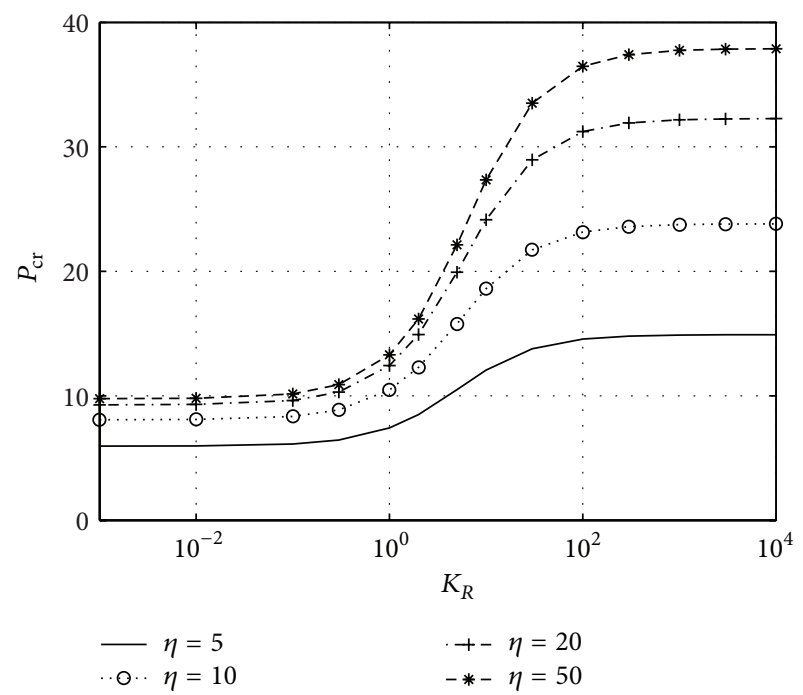

(b) $E_{s}=0$

Figure 6: Influence of $K_{R}$ on $P_{\text {cr }}$ for different types of foundation and for different $\eta$.

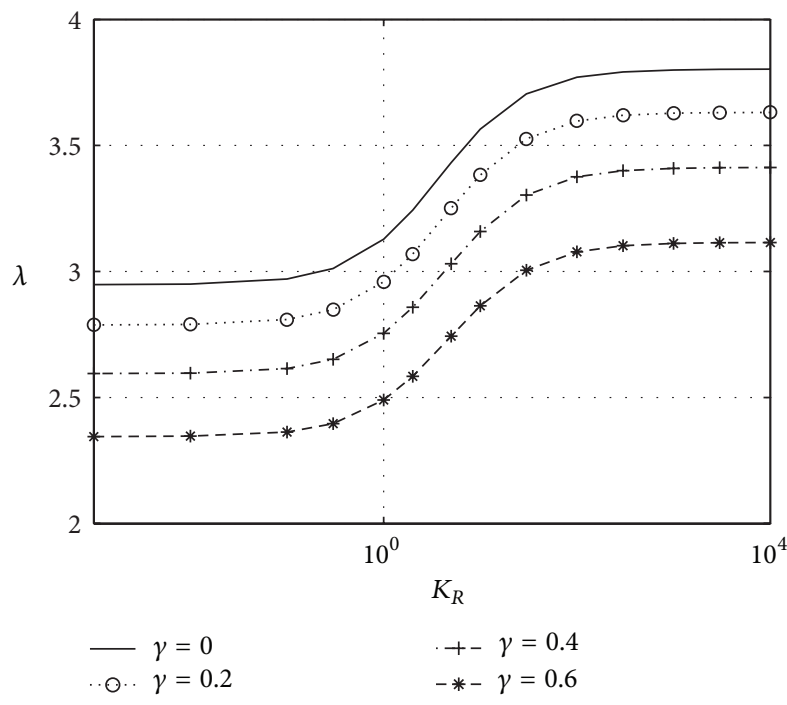

(a) No foundation $\left(E_{s}=0\right)$

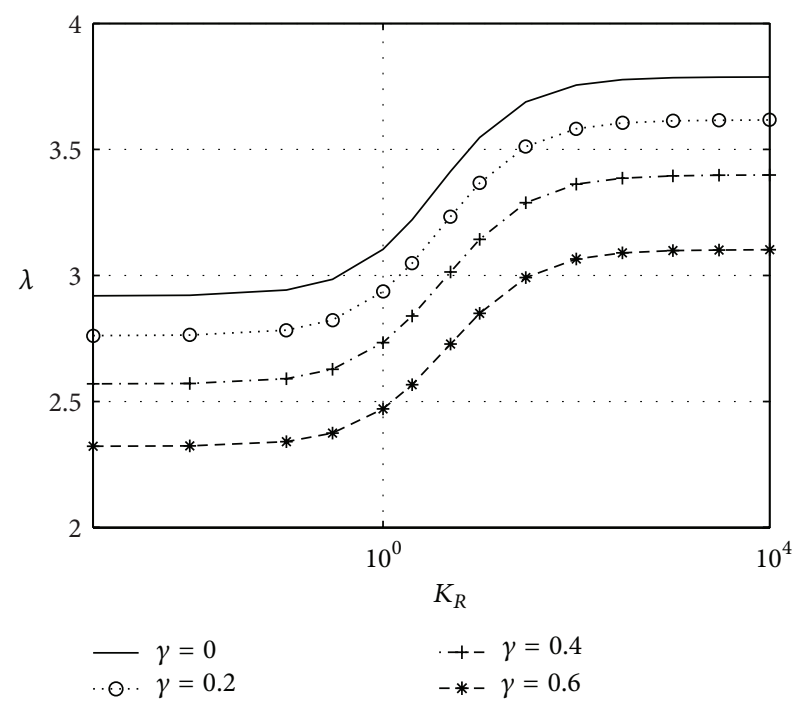

(b) Stiff foundation $\left(E_{s}=10^{8}\right)$

Figure 7: Influence of $K_{R}$ on $\lambda$ for different loading ratios $(\eta=10)$.

the high stiffness of the beam relative to the foundation. Also, it is found that the influence of rotational stiffness increases with the increase in the slenderness ratio. Also, it is found that the natural frequency decreases as the axial load increases till the axial load approaches its critical values; then the natural frequency approaches zero.

4.3. Forced Vibration Analysis. The weakening of ends elastic restraints is represented by the variation of the restraint stiffness. The variation of normalized maximum response amplitude $\left(W^{*}\right)$ with the ends rotational stiffness $\left(K_{R}\right)$ is indicated in Figure 8 for different loading types. Case (a) represents the effects of uniform loading functions, case (b) represents the effect of linear loading functions, and case (c) represents the effect of quadratic loading functions. As the case of $K_{R}=$ 0 represents the P-P beams, it is obvious from the figures that the displacement due to dynamic loading is greater than those for static loading due to the inertia force interference at $K_{R}=0$. Also, it is clear that, as $K_{R}$ increases, the stiffness of the beam increases and the response amplitude decreases. It is obvious that, at a certain combination of the system parameters, the resonance condition is approached and unbounded response amplitude is detected. As the axial load increases, the variations of the end rotational stiffness may cause the system to reach the resonance conditions and the amplitude becomes unbounded. If the damping is taken into consideration, the amplitude will possess a finite value but such condition is to be prevented. However, it is concluded 

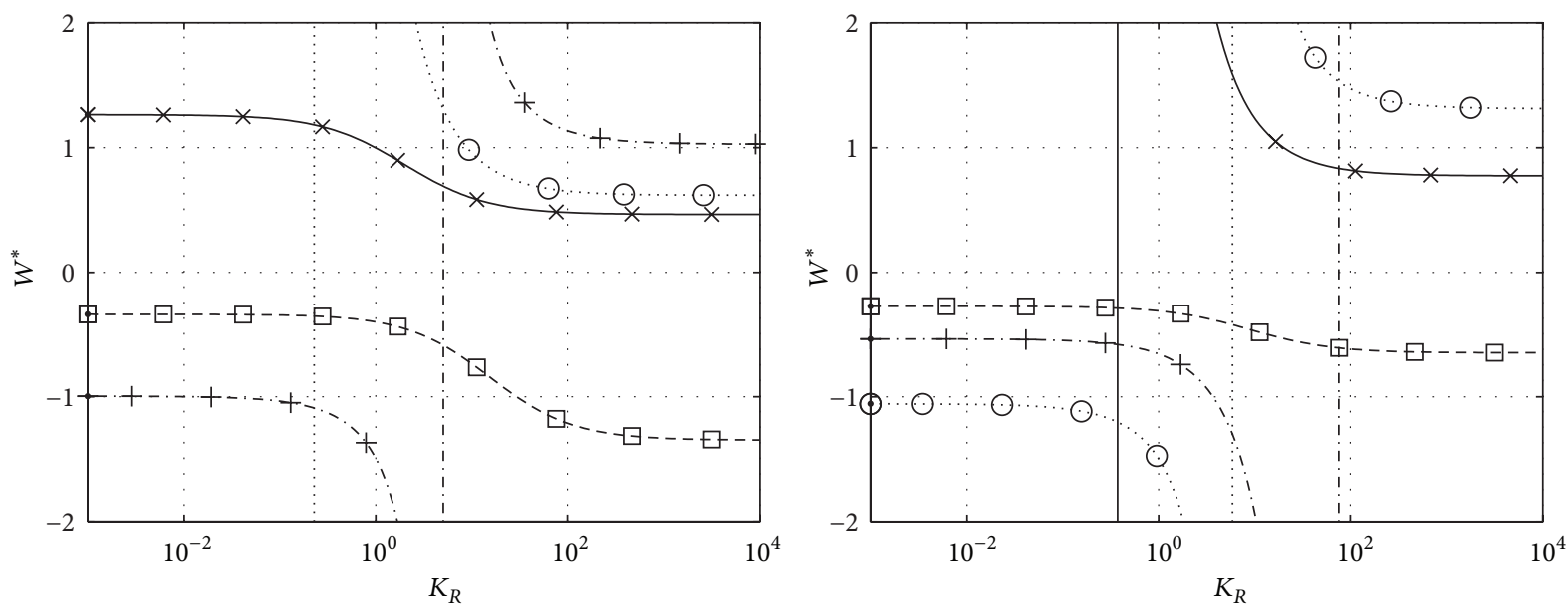
$\leftarrow p=0$
$\odot p=5$
$+p=10$
$-\square-p=20$
$\begin{aligned} \times p & =0 \\ \odot P & =5\end{aligned}$
$+p=10$
$-\square-p=20$

(a) Uniform loading function
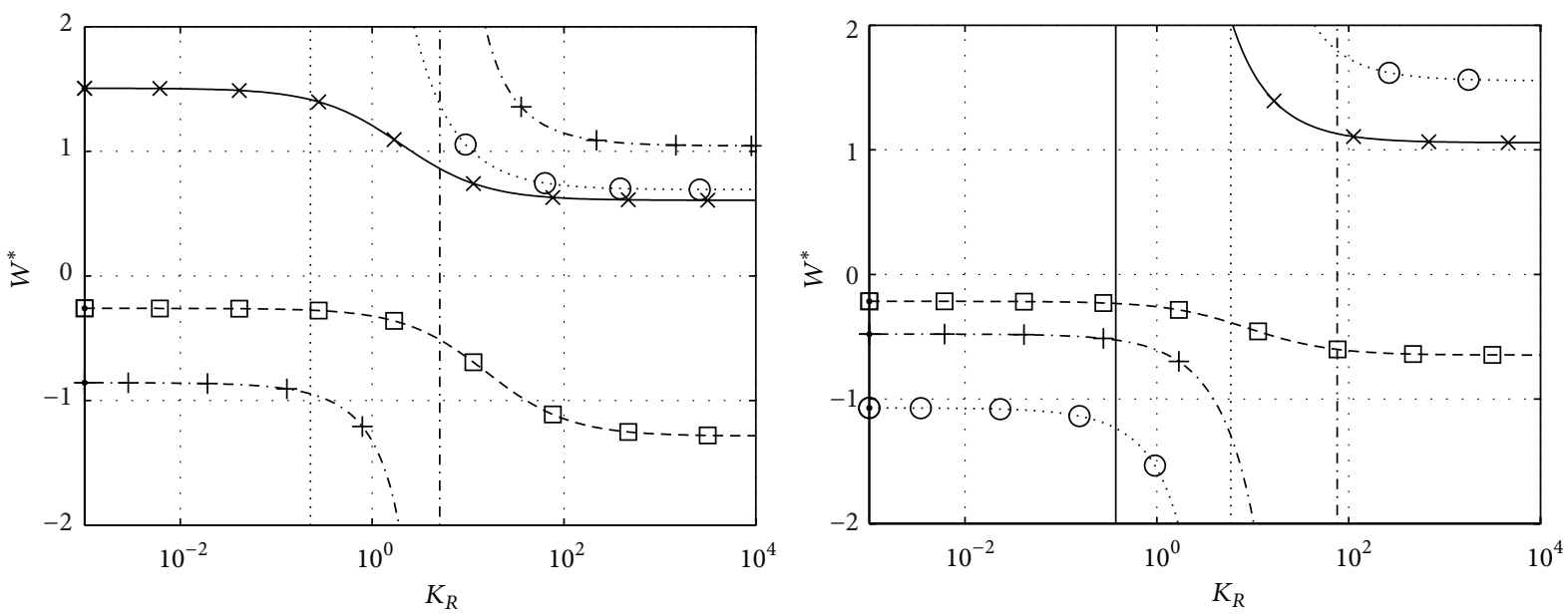
$\star p=0$
$+p=10$
$\odot p=5$
$-\square-p=20$
$* p=0$
.) $p=5$
$+p=10$
$-\square-p=20$

(b) Linear loading function
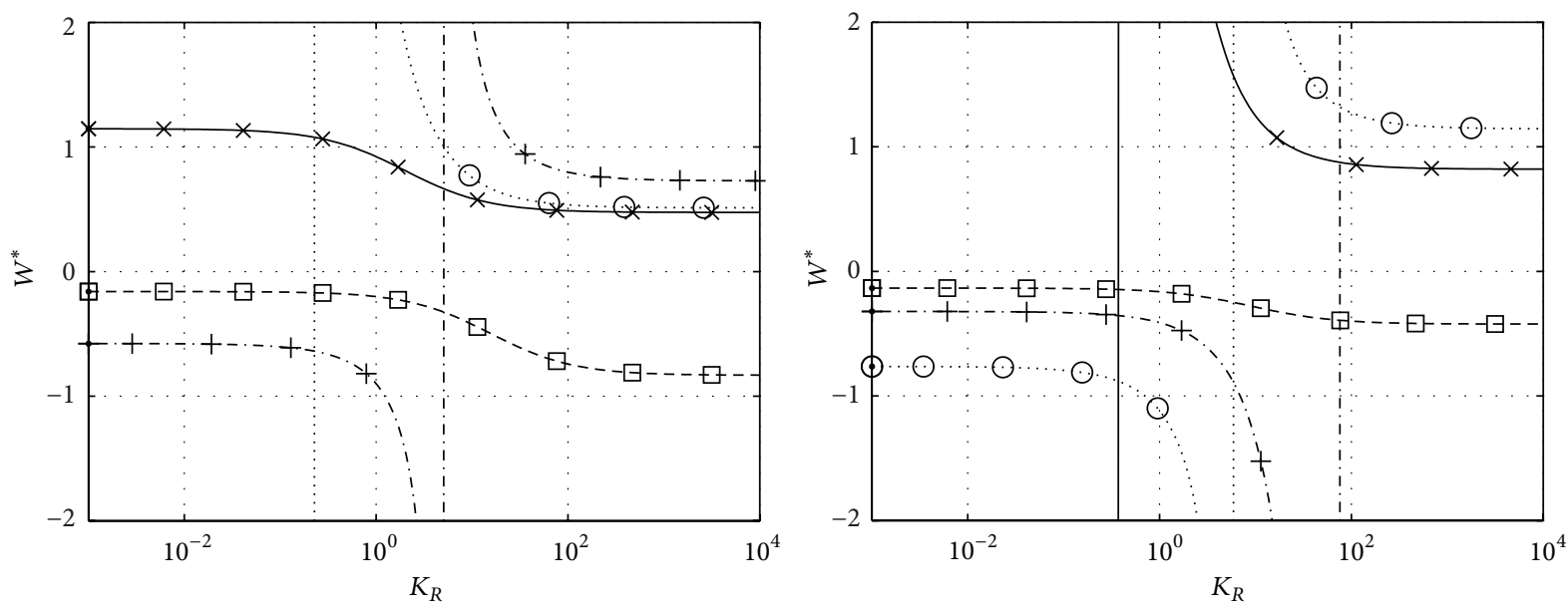

$\begin{array}{ll}* p=0 & +p=10 \\ \odot p=5 & -\square-p=20\end{array}$

$\begin{array}{ll}* p=0 & +p=10 \\ \odot p=5 & -\square-p=20\end{array}$

(c) Quadratic loading function ((1) $E_{s}=0$, (2) $E_{s}=10^{8}$ )

FIgURE 8: Variation of $W^{*}$ with $K_{R}$ for different axial loading ratio $(\eta=10)$. 
that the weakening of the end restraints may offer a parameters combination coinciding with the resonance conditions for the first mode or one of the higher modes and unbounded amplitudes may be reached.

\section{Conclusions}

The RDM is used to investigate the stability behavior of axially loaded cantilever Timoshenko beam resting on twoparameter foundation. In addition, the analysis includes the investigation of Timoshenko beams resting on twoparameter foundation and subjected to different types of lateral excitation. The supports at the beam ends are assumed of the elastic type to investigate the impact of the support weakening on the beam behavior. Both the effect of rotational inertia and the correction of the shear stress due to axial loading are taken into consideration which decreases the beam stiffness. It is concluded that the significance of the foundation on the Timoshenko beams $(\eta<20)$ behavior is negligible; the effect of end restraints is more noticeable for slender beams and the natural frequency decreases as the axial load increases. However, for the case of the forced vibration, the resonance conditions may result from the weakening of the end supports and unbounded response amplitudes may be reached. The analysis depicts the simplicity and accuracy of the RDM in tackling the boundary value problems.

\section{Conflict of Interests}

The authors declare that there is no conflict of interests regarding the publication of this paper.

\section{References}

[1] P. Ruta, "The application of Chebyshev polynomials to the solution of the nonprismatic Timoshenko beam vibration problem," Journal of Sound and Vibration, vol. 296, no. 1-2, pp. 243-263, 2006.

[2] K. Kausel, "Nonclassical modes of unrestrained shear beams," Journal of Engineering Mechanics, vol. 128, no. 6, pp. 663-667, 2002.

[3] R. Attarnejad, A. Shahba, and S. J. Semnani, "Application of differential transform in free vibration analysis of timoshenko beams resting on two-parameter elastic foundation," Arabian Journal for Science and Engineering, vol. 35, no. 2B, pp. 125-132, 2010.

[4] M. Taha and M. A. Nassar, "Analysis of stressed Timoshenko beams on two parameter foundations," KSCE Journal of Civil Engineering, vol. 19, no. 1, pp. 173-179, 2015.

[5] L. Majkut, "Free and forced vibration of Timoshenko beams described by single difference equation," Journal of Theoretical and Applied Mechanics, vol. 47, no. 1, pp. 193-210, 2009.

[6] F. Y. Cheng and C. P. Pantelides, "Dynamic timoshenko beamcolumn on elastic media," Journal of Structural Engineering, vol. 114, no. 7, pp. 1524-1550, 1988.

[7] B. Geist and J. R. Mclaughlin, "Double eigen value for the Timoshenko beam," Applied Mathematics Letters, vol. 10, pp. 129-134, 1997.
[8] C.-N. Chen, "DQEM vibration analyses of non-prismatic shear deformable beams resting on elastic foundations," Journal of Sound and Vibration, vol. 255, no. 5, pp. 989-999, 2002.

[9] A. L. G. Monsalve, Z. D. G. Medina, and A. J. D. Ochoa, “Timoshenko beam-column with generalized end conditions on elastic foundation: dynamic-stiffness matrix and load vector," Journal of Sound and Vibration, vol. 310, no. 4-5, pp. 1057-1079, 2008.

[10] T. Kocaturk and M. Simsek, "Free vibration analysis of Timoshenko beams under various boundary conditions," Sigma Journal of Engineering and Natural Sciences, vol. 1, pp. 30-44, 2005.

[11] D. K. Nguyen, "Free vibration of prestressed Timoshenko beams resting on elastic foundations," Vietnam Journal of Mechanics, vol. 29, no. 1, pp. 1-12, 2012.

[12] N. M. Auciello, "Vibrations of Timoshenko beams on two parameter elastic soil," Engineering Transactions, vol. 56, no. 3, pp. 187-200, 2008.

[13] M. Taha, "Recursive differentiation method for boundary value problems: application to analysis of a beam-column on an elastic foundation," Journal of Theoretical and Applied Mechanics, vol. 44, no. 2, pp. 57-70, 2014.

[14] M. Taha and E. H. Doha, "Recursive differentiation method: application to the analysis of beams on two parameter foundations," Journal of Theoretical and Applied Mechanics, vol. 53, no. 1, pp. 15-26, 2015.

[15] S. P. Timoshenko and J. M. Gere, Theory of Elastic Stability. Engineering Societies Monographs, McGraw-Hill Book, New York, NY, USA, 1961. 


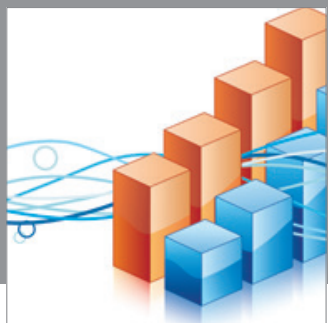

Advances in

Operations Research

mansans

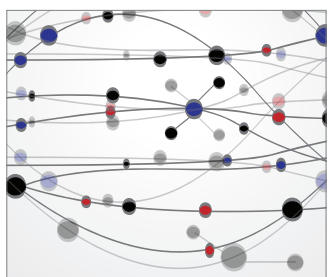

The Scientific World Journal
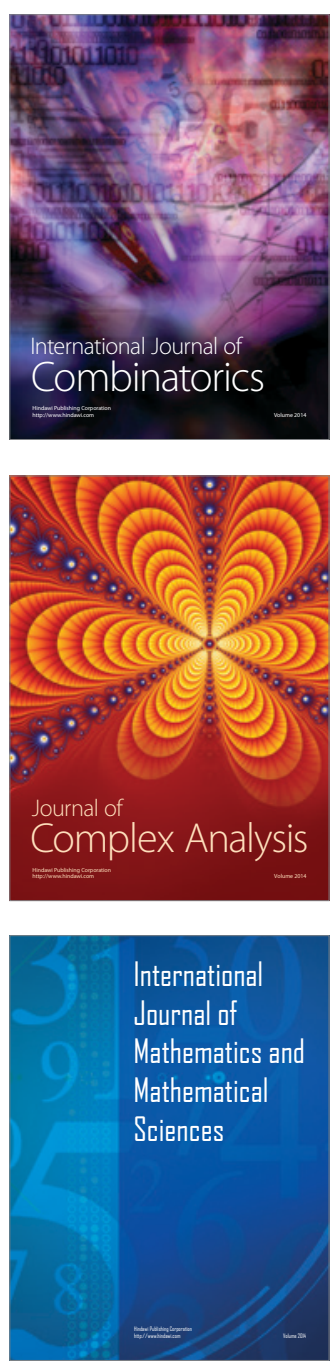
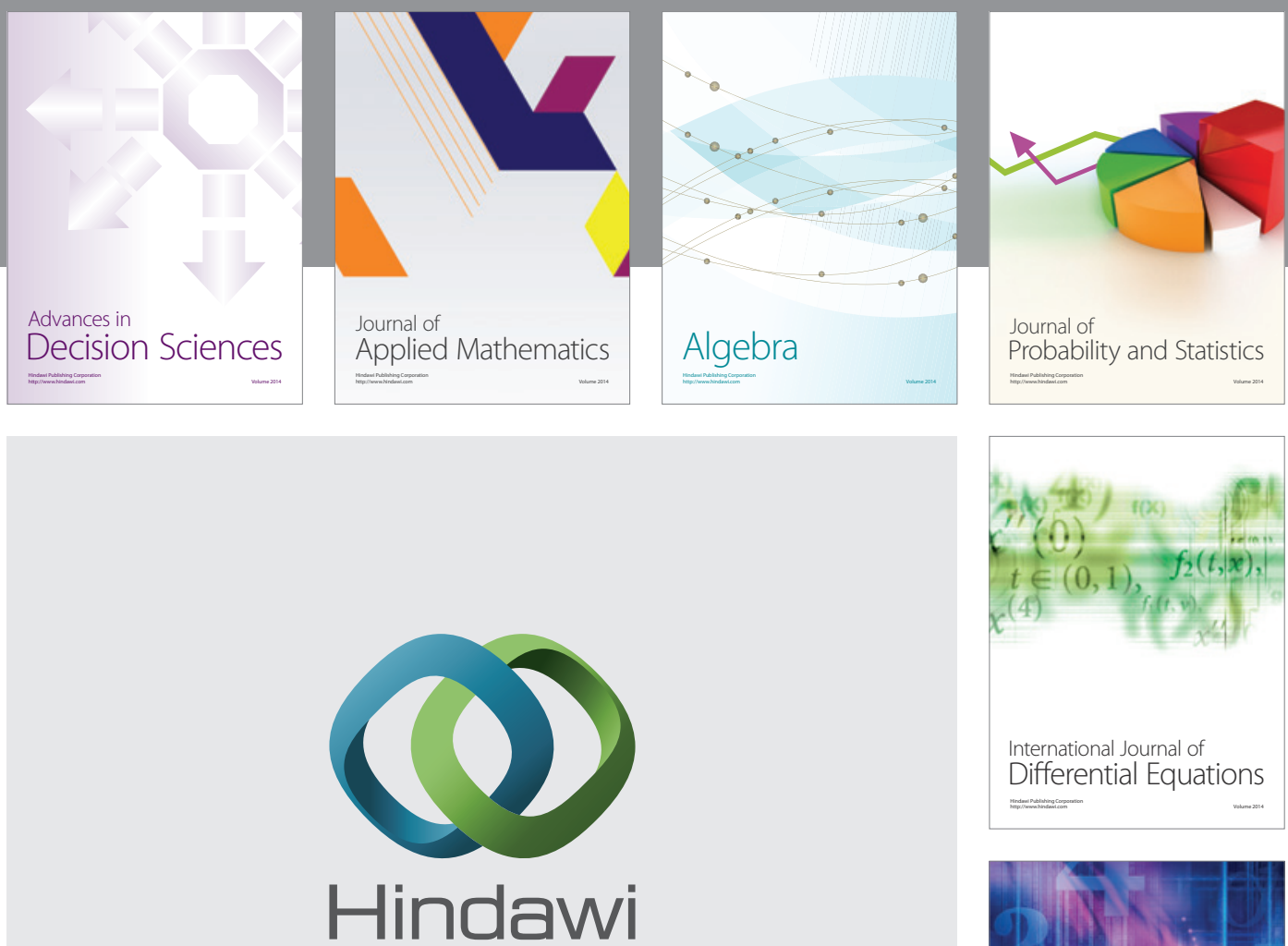

Submit your manuscripts at http://www.hindawi.com
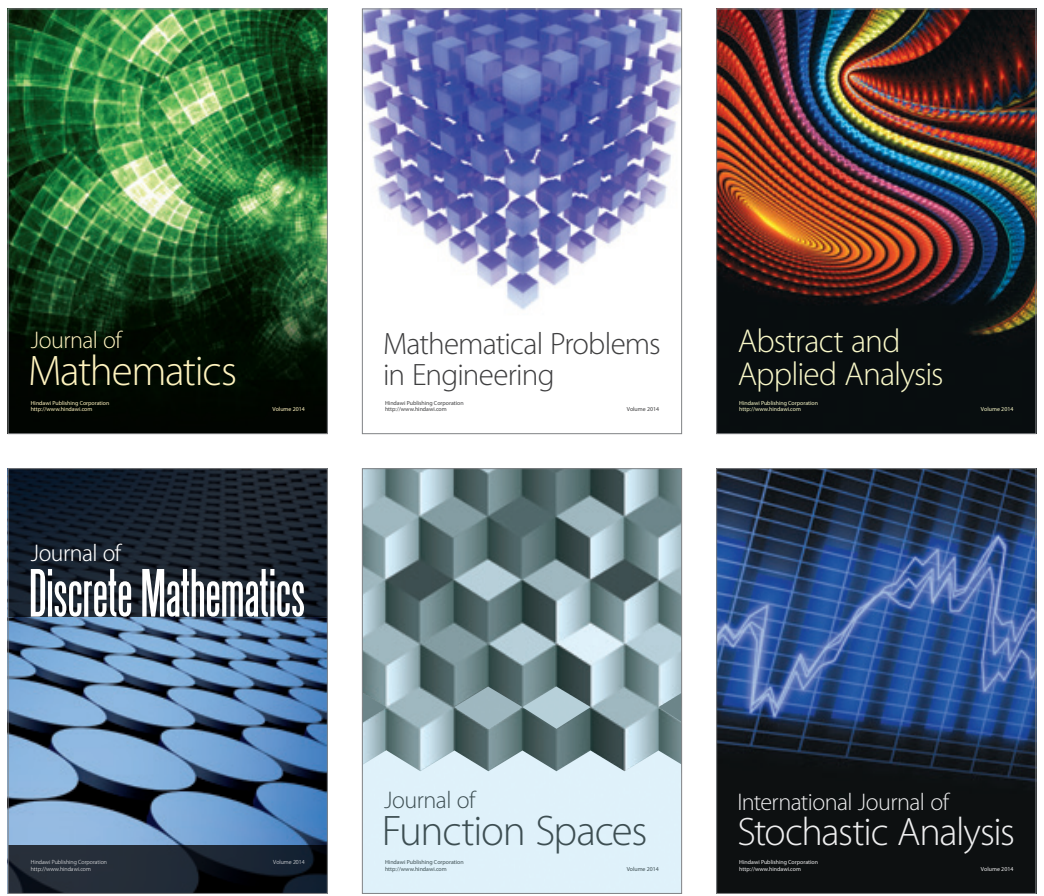

Journal of

Function Spaces

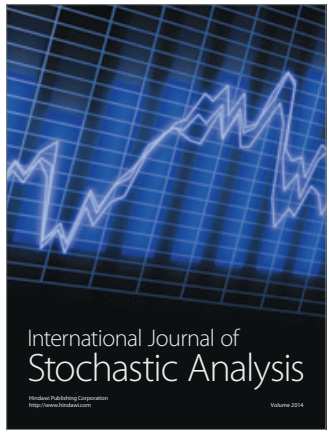

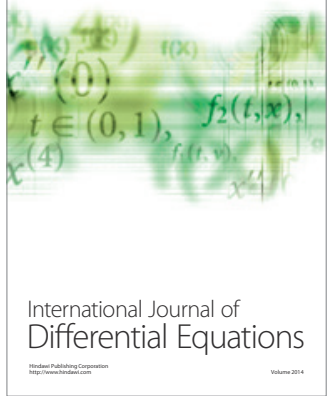
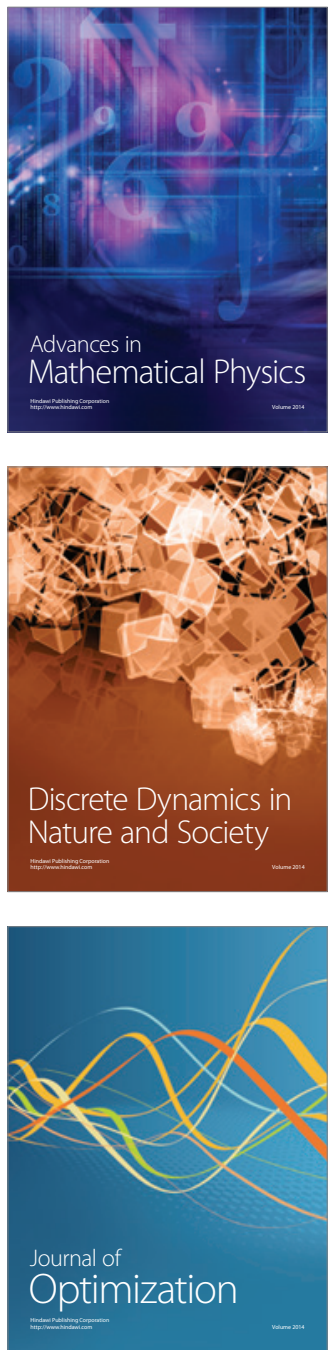